\title{
Survival and prognostic factors for survival, cancer specific survival and disease free interval in 239 patients with Hurthle cell carcinoma: a single center experience
}

\author{
Branisav Oluic ${ }^{1 *}$, Ivan Paunovic ${ }^{2,3}$, Zlatibor Loncar ${ }^{1,3}$, Vladimir Djukic ${ }^{1,3}$, Aleksandar Diklic $^{2,3}$, Milan Jovanovic $^{2}$, \\ Zeljko Garabinovic ${ }^{4}$, Nikola Slijepcevic ${ }^{2}$, Branislav Rovcanin ${ }^{2}$, Dusan Micic ${ }^{1}$, Aleksandar Filipovic ${ }^{5}$ \\ and Vladan Zivaljevic ${ }^{2,3}$
}

\begin{abstract}
Background: Hurthle cell carcinoma makes up 3 to 5\% of all thyroid cancers and is considered to be a true rarity. The aim of our study was to analyze clinical characteristics and survival rates of patients with Hurthle cell carcinoma.

Methods: Clinical data regarding basic demographic characteristics, tumor grade, type of surgical treatment and vital status were collected. Methods of descriptive statistics and Kaplan-Meier survival curves were used for statistical analysis. Cox proportional hazards regression was used to identify independent predictors.

Results: During the period from 1995 to 2014, 239 patients with Hurthle cell carcinoma were treated at our Institution. The average age of the patients was 54.3, with female to male ratio of 3.6:1 and average tumor size was $41.8 \mathrm{~mm}$. The overall recurrence rate was $12.1 \%$, with average time for relapse of 90.74 months and average time without any signs of the disease of 222.4 months. Overall 5-year, 10-year and 20-year survival rates were 89.4\%, 77.2\%, 61.9\% respectively. The 5-year, 10-year and 20-year cancer specific survival rates were $94.6 \%, 92.5 \%, 87.4 \%$, respectively. When disease free interval was observed, 5-year, 10-year and 20-year rates were $91.1 \%, 86.2 \%, 68.5 \%$, respectively. The affection of both thyroid lobes and the need for reoperation due to local relapse were unfavorable independent prognostic factors, while total thyroidectomy as primary procedure was favorable predictive factor for cancer specific survival.
\end{abstract}

Conclusion: Hurthle cell carcinoma is a rare tumor with an encouraging prognosis and after adequate surgical treatment recurrences are rare.

Keywords: Thyroid gland, Hurthle cell carcinoma, Survival, Cancer specific survival, Disease free interval

\section{Background}

Thyroid gland cancers are relatively rare tumors which represent approximately $1 \%$ of all malignant tumors, and in the structure of all malignant tumors-related lethal outcomes, they are accounted for less than $0.5 \%$. Hurthle cell carcinoma or oxyphilic carcinoma makes up 3 to $5 \%$ of all thyroid cancers and, therefore, is considered to be a true rarity $[1,2]$.

\footnotetext{
* Correspondence: branislavoluic@gmail.com

${ }^{1}$ Emergency Center, Clinical Center of Serbia, Pasterova 2, Belgrade 11000, Serbia

Full list of author information is available at the end of the article
}

According to the current classification of the World Health Organization, Hurthle cell carcinoma represents a variant of follicular carcinoma of the thyroid gland. Still, genetic studies have shown that these tumors have a completely different oncogenesis; furthermore, there are differences regarding clinical characteristics if compared to papillary and follicular carcinoma [3]. In order to be classified as a Hurthle cell carcinoma, a tumor should predominantly consist of the Hurthle cells, which originate from follicular epithelium of the thyroid gland.

As for all other thyroid cancers, surgery represents primary and basic treatment method for Hurthle cell carcinoma, as well. When it comes to radioiodine 
treatment for this tumor, there are still ongoing debates, since it bonds radioactive iodine slightly lower compared to other well-differentiated thyroid cancers.

In the past, this type of thyroid cancer was associated with prognosis which was worse than the prognosis of papillary and follicular cancers $[1,4]$.

Given the low incidence rate, studies which have examined the clinical characteristics and optimal treatment methods of Hurthle cell carcinoma are rare and mostly based on individual institution's experience. When it comes to survival rates, cancer specific survival rates, disease free interval, as well as prognostic factors for this tumor, literature is particularly deficient.

The aim of our paper was to analyze the basic clinical and pathological characteristics of this tumor and to determine the overall survival, cancer-specific survival and disease free interval in patients with Hurthle cell carcinoma on a representative number of subjects. The second aim was to determine and analyze prognostic factors and predictors of survival in patients with Hurthle cell carcinoma.

\section{Methods}

A retrospective cohort study was conducted at our Institution, from January 1st 1995 until December 31st 2014. The study included all patients in whom the diagnosis of oxyphilic thyroid cancers was confirmed by a definitive histopathological examination. All preparations were reexamined by a pathologist, experienced in the field of endocrine surgery, so the diagnosis of Hurthle cell carcinoma was confirmed.

Based on the insight into medical documentation (medical history and an electronic database implemented in everyday work) we have collected data of all patients regarding the following: basic demographic characteristics of patients (gender, age), duration of disease, familial form of cancer, clinical features (TNM (Tumor Nodes Metastasis) classification of tumors, associated thyroid gland diseases, thyroid hormone levels, antibodies and markers' levels, regional lymph-node metastasis, distant metastasis, infiltration of adjacent organs), histopathologic characteristics of the tumor, surgical treatment (type of surgery, the year of the procedure, the experience of the surgeon, reoperation due to local relapse), other treatment forms (radioiodine therapy, radiotherapy, substitutional-suppressive levothyroxine therapy) and associated diseases (diabetes, other malignant tumors).

The duration of illness was defined as the period from the time of diagnosis of thyroid gland changes until the time of surgery. Familial form of the disease was defined if patients had the first degree relatives who have undergone surgery due to Hurthle cell carcinoma. Staging of the tumor was carried out on the basis of TNM classification, which was valid at the time of operation, based on the histopathological findings. Data on the size of the tumor were collected separately, so no reclassification was done due to changes in criteria in 2002 [5]. Associated thyroid diseases were determined based on preoperative or histopathological findings. Serum levels of thyroid hormones, antibodies and markers (thyroidstimulating hormone, triiodothyronine, thyroxine, thyroperoxidase antibody and thyroglobulin) were measured just before the surgery. All patients were euthyroid at the time of surgery. Patients with hyperthyroidism were treated until the euthyroid state was achieved and subsequently treated surgically. Data regarding regional lymph node metastases and distant metastases at the time of operation were also collected. Infiltration of the surrounding tissue was determined based on intraoperative and histopathological findings. Characteristics of the tumor were determined based on histopathological findings: invasive or minimally invasive type of tumor, tumor size, capsule invasion, vascular invasion, multicentricity, involvement of one or both lobes (Fig. 1).

Data regarding patients' survival/death (whether patients were still alive and if not when they died) were obtained through the contact with patients or members of their families. We have also collected data of local recurrences of the tumor or metastases and further treatment methods. All patients received substitutional-suppressive levothyroxine therapy in order to prevent recurrence of the tumor.

Until 2006, radioiodine was applied only in cases of advanced tumors and later on in all cases in which total thyroidectomy was performed, where tumor was over T1.

We have particularly analyzed surgical treatment of Hurthle cell carcinomas. Patients were classified into groups according to the type of operation: total thyroidectomy (total thyroidectomy or near total thyroidectomy) and hemithyroidectomy group (lobectomy or near lobectomy). Whenever enlarged lymph nodes were present (seen by an ultrasound examination or intraoperatively) appropriate dissection was done. In patients in whom lobectomy was performed, we have searched the data regarding the completion of thyroidectomy. Completion of total thyroidectomy following lobectomy was done when the contralateral side was altered or when there was clearly unilateral invasive cancer, so ablative radioiodine therapy was indicated. When patients were re-operated following total thyroidectomy due to local relapse, or when the focus of the tumor was found during the completion of total thyroidectomy following lobectomy, we have marked that those patients had recurrence of the cancer.

\section{Statistical analysis}

Statistical analyses were performed using SPSS 22.0 software (SPSS Inc., Chicago, IL). 


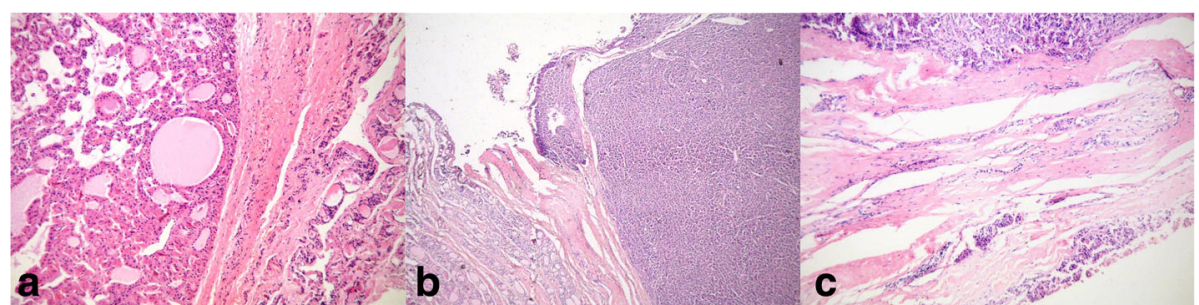

Fig. 1 Hurthle cell carcinoma: a) without capsular or vascular invasion, b) capsular invasion, c) vascular invasion

The quantitative variables were expressed as mean \pm standard deviation (SD), while the categorical ones were presented as percentages. Kaplan-Meier survival curves were used for determination of overall survival, cancer specific survival and disease free interval for each observed variable. The log rank test was used to determine the overall survival rate, cancer specific survival rate and disease-free survival interval. At last, univariate Cox regression analysis was performed in order to determine which variables were significantly associated with survival. Those variables that have showed significant association with survival in univariate analysis, at the level of significance of $p \leq 0.05$, were included in multivariate analysis.

\section{Results}

During 20-years period covered by the study, 13.385 patients were surgically treated due to thyroid gland diseases at our highly specialized center for endocrine surgery. Out of this number, a total of 3.344 thyroid cancers (29.98\%) were histopathologically verified. Hurthle cell carcinoma was present in 239 patients (diagnosed by histopathologic examinations), which represents $7.1 \%$ of all thyroid cancers and $1.8 \%$ of all patients who have undergone thyroid gland surgery.

Table 1 presents demographic characteristics of patients and basic characteristics of carcinomas. The average age of patients with Hurthle cell carcinoma at the time of surgery was $54.3 \pm 13.7$ years; the youngest patient was 20 and the oldest 89 years old. The vast majority of affected individuals were in the 6th decade of their life. Females were more affected and female to male ratio was 3.6:1.

The average duration of the disease, from the moment of diagnosis of the alteration in the thyroid gland up to surgery was 77 months. In two patients $(0.8 \%)$ there was a positive family history of thyroid oxyphilic carcinoma (in one case, the patient's father and in the other, the patient's mother).

The median tumor size in surgically treated patients due to Hurthle cell carcinoma was $41.8 \mathrm{~mm}$ (range $4 \mathrm{~mm}-160 \mathrm{~mm}$ ). Most of the tumors were classified as minimally invasive, in 102 patients (67.1\%). Invasion of the capsule was present in 152 patients (69.7\%) and vascular invasion in 146 patients (67\%). Tumor usually had one focus, in 167 patients (76.6\%). In the group of patients in whom bilateral procedure was performed (162 patients), the tumor was unilateral in 116 patients (71.6\%). The tumor was most often in the T2 stage (112 patients, 46.9\%) (Table 1).

Preoperative values of thyroglobulin were elevated in 52 patients (73.2\%). Regional lymph nodes metastases at the time of surgery existed in 6 patients $(2.8 \%)$, while the local infiltration of surrounding tissue was present in 33 patients $(13.8 \%)$. In $7.7 \%$ of the patients whose lymph nodes were extirpated during the primary surgery, lymphatic metastases were present. Twelve patients (5\%) also had micropapillary carcinoma; in 3 patients, oxyphilic carcinoma was developed focally within benign lesions: 2 in follicular adenoma and one in colloid adenoma (Table 2). Another malignancy existed in 19 patients $(8 \%)$ and the most common localization of the other tumor was genitourinary system (7 patients, 36.9\%).

\section{Surgical procedures}

In patients surgically treated for Hurthle cell carcinoma, the most commonly performed primary procedure was total thyroidectomy, in 160 patients (66.9\%), while in 66 patients (27.6\%) lobectomy was done (Table 2). Completion of thyroidectomy following lobectomy was performed in 21 patients, which represent $31.8 \%$ of all lobectomies. In 12 of these patients, focus of oxyphilic carcinoma was found on the contralateral side, accounting for $57.1 \%$ of all patients in whom completion of thyroidectomy was performed, or $18.2 \%$ of all patients in whom lobectomy was done. Completion was performed after an average of $14.4 \pm 13.5$ months (range, 3-36 months). In 78 patients central or lateral neck dissection was performed during the initial procedure and metastases in the lymph nodes were present in 6 patients (7.7\%). The average length of surgeons' specialist experience was $16.3 \pm 9.8$ years (range, $0-35$ years) (Table 1). Radioiodine was applied in 65 patients (36.9\%), most commonly once (in 58 patients). 
Table 1 Demographic and clinical characteristics of patients with Hurthle cell carcinoma

\begin{tabular}{|c|c|c|c|c|c|}
\hline Variable & Number & Percent & Radioiodine ablation after surgery & & \\
\hline Gender & & & Yes & 65 & 36,9 \\
\hline Female & 187 & 78.2 & No & 111 & 63,1 \\
\hline Males & 52 & 21,8 & Surgeon experience & & \\
\hline Age & $54,3 \pm 13,7$ & & resident & 11 & 4,6 \\
\hline $20-29$ & 10 & 4,2 & specialist $1-5$ years & 20 & 8,4 \\
\hline $30-39$ & 28 & 11,7 & specialist 6-10 years & 57 & 23,8 \\
\hline $40-49$ & 46 & 19,2 & specialist over 10 years & 151 & 63,2 \\
\hline
\end{tabular}

60-69

$>70$

PT tumor stage

$\begin{array}{ll}\mathrm{T} 1 & 19 \\ \mathrm{~T} 2 & 1 \\ \mathrm{~T} 3 & 75 \\ \mathrm{~T} 4 & 33 \\ \mathrm{~N} \text { stage } & \end{array}$

NO

N1a

N1b

Nx

Tumor invasiveness

minimally invasive

widely invasive

Tumor size $(\mathrm{mm})$

$$
<39
$$$$
\geq 40
$$

Capsular invasion

transcapsular

no or minimal

Vascular invasion

positive

no or minimal

Number of tumor focuses

one focus

multicentric

Regional tumor infiltration

positive

negative

Thyroglobulin

normal values $(<68 \mathrm{ng} / \mathrm{mL})$

elevated values (>68 ng/mL)
66
Table 1 Demographic and clinical characteristics of patients with Hurthle cell carcinoma (Continued)

\section{Outcomes}

At the time of completion of the study, with an average follow-up period of $89.5 \pm 60.2$ months (range 1-234), 36 patients have died. Minimum follow-up period was one year (except for those patients who have died earlier). Thyroid gland disease was the cause of death in 13 patients (6.4\%), i.e. in $36.1 \%$ of all deceased patients. At the moment of death, the average age of patients with Hurthle cell carcinoma who died because of thyroid pathology was $64.7 \pm 12.1$ years. On the other hand, average age at the moment of death of patients who were operated for Hurthle cell carcinoma and died due to other reasons was $74.4 \pm 9.2$ years. Average overall survival was 186.6 months (95\% Confidence interval (CI): 173.3-199.9). An overall one-year survival rate was $96.6 \%$, five-year survival was $89.4 \%$, ten-year was $77.2 \%$ and twenty-year survival rate was $61.9 \%$. (Fig. 2).

Univariate analysis for overall survival revealed that the following 6 factors were associated with shorter survival rate: age, $\mathrm{T}$ stadium, tumor type, tumor size, regional tumor infiltration, affection of both lobes, reoperation due to relapse and hypertension (Table 3).

Table 2 Primary procedure and associated thyroid gland diseases in patients with Hurthle cell carcinoma

\begin{tabular}{lll}
\hline Type of surgery & Number & Percent \\
\hline Total thyroidectomy & 160 & 66.9 \\
Lobectomy & $66^{\mathrm{a}}$ & 27.6 \\
Dunhill's procedure & 10 & 4.2 \\
Tumor reduction & 3 & 1.3 \\
Associated thyroid pathology & 12 & \\
Micropapillary thyroid carcinoma & 4 & 5.0 \\
Papillary thyroid carcinoma & 1 & 1.7 \\
Medullary carcinoma & 2 & 0.4 \\
Graves' disease & 18 & 0.8 \\
Thyroiditis & 3 & 7.5 \\
Benign tumor & 40 & 1.3 \\
Total & 40.7 \\
\hline in 21 patients total thyroidectomy was performed after lobectomy &
\end{tabular}




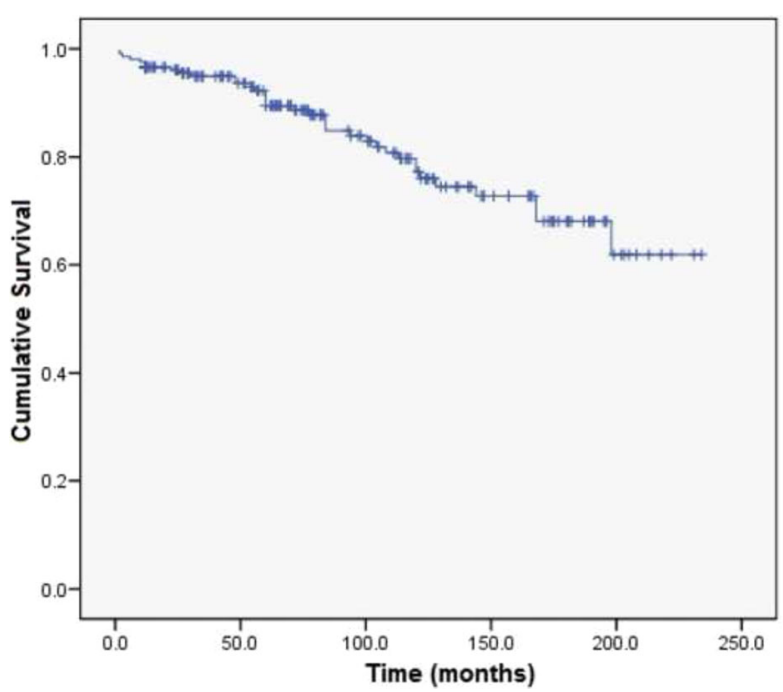

- Survival Function

+ Censored

Fig. 2 Kaplan-Meier overall survival curve

Table 3 Univariate and multivariate statistical analysis of overall survival

\begin{tabular}{|c|c|c|c|c|c|c|}
\hline \multirow[b]{2}{*}{ Factor } & \multicolumn{3}{|c|}{ Univariate } & \multicolumn{3}{|c|}{ Multivariate } \\
\hline & $p$ & OR & $95 \% \mathrm{Cl}$ & $p$ & OR & $95 \% \mathrm{Cl}$ \\
\hline Gender (male vs. female) & 0,281 & 0,67 & $0,32-1,39$ & & & \\
\hline Age (years) (<54 vs. $\geq 55)$ & 0,001 & 8,92 & $3,63-21,92$ & 0,002 & 5,92 & $1,95-17,96$ \\
\hline Disease duration (years) $(<5$ vs. $\geq 5)$ & 0,421 & 1,31 & $0,68-2,53$ & & & \\
\hline T stadium ( $T 1$ and $T 2$ vs. $T 3$ and $T 4$ ) & 0,001 & 4,47 & $2,03-9,82$ & 0,002 & 4,31 & $1,67-11,09$ \\
\hline $\mathrm{N}$ stadium (NO and Nx vs. N1a and N1b) & 0,601 & 1,46 & $0,35-6,11$ & & & \\
\hline Tumor type (minimally vs. widely invasive) & 0,044 & 1,96 & $1,01-3,79$ & & & \\
\hline Tumor size $(\mathrm{mm})(\leq 39$ vs. $>40)$ & 0,004 & 4,19 & $1,57-11,19$ & & & \\
\hline Capsular invasion (positive vs. no or minimal) & 0,38 & 1,42 & $0,65-3,11$ & & & \\
\hline Vascular invasion (positive vs. no or minimal) & 0,287 & 0,61 & $0,25-1,50$ & & & \\
\hline Number of tumor focuses (one vs. multicentric) & 0,104 & 1,84 & $0,88-3,85$ & & & \\
\hline Affection of both lobes (yes vs. no) & 0,004 & 2,93 & $1,4-6,12$ & 0,005 & 3,29 & $1,42-7,62$ \\
\hline Regional tumor infiltration (yes vs. no) & 0,003 & 0,35 & $0,17-0,7$ & & & \\
\hline Primary procedure (total thyroidectomy vs. less than total) & 0,65 & 1,18 & $0,56-2,48$ & & & \\
\hline Total thyroidectomy after lobectomy (yes vs. no) & 0,19 & 0,44 & $0,12-1,53$ & & & \\
\hline Type of procedure overall (total thyroidectomy vs. less than total) & 0,836 & 0,92 & $0,4-2,09$ & & & \\
\hline Reoperation due to relapse (yes vs. no) & 0,035 & 0,407 & $0,17-0,94$ & 0,016 & 0,3 & $0,11-0,79$ \\
\hline Surgeon's experience (years) (<10 vs. $10+)$ & 0,25 & 0,66 & $0,32-1,33$ & & & \\
\hline Radioiodine ablation (yes vs. no) & 0,43 & 1,88 & $0,39-9,08$ & & & \\
\hline Diabetes mellitus (yes vs. no) & 0,3 & 0,53 & $0,16-1,77$ & & & \\
\hline Hypertension (yes vs. no) & 0,002 & 0,32 & $0,16-0,65$ & & & \\
\hline Other malignancies (yes vs. no) & 0,275 & 0,55 & $0,19-1,59$ & & & \\
\hline Thyroglobulin (ng/mL) (<300 vs. $>300)$ & 0,925 & 1,11 & $0,11-10,9$ & & & \\
\hline
\end{tabular}


Multivariate regression analysis showed that independent unfavorable prognostic factors for overall survival were age over 55 (odds ratio (OR) 5.92, 95\% CI 1.9517.96), $\mathrm{T} 3$ and $\mathrm{T} 4$ tumor stadium (OR 4.31, 95\% CI 1.67-11.09), affection of both lobes (OR 3.29, 95\% CI $1.42-7.62)$ and re-operation due to relapse (OR 0.3, 95\% CI 0.11-0.79).

Average cancer specific survival was 216.4 months (95\% CI: 207.1 to 225.7 ). Cancer specific survival rate after one year was $98 \%$, after five years was $94.6 \%$, after ten years was $92.5 \%$ and twenty-year survival rate was 87.4\%. (Fig. 3).

The results of univariate analysis for cancer specific survival showed that age, $\mathrm{T}$ stadium, regional tumor infiltration, affection of both lobes, primary operation and reoperation due to relapse contribute to shorter survival (Table 4). The results of multivariate regression analysis revealed that independent prognostic factors for cancer specific survival were affection of both lobes (OR 8.09, 95\% CI 2.12-30.79) and reoperation due to recidivism (OR 0.1, 95\% CI 0.03-0.39), as unfavorable prognostic factors, and that total thyroidectomy for primary operation (OR 8.46, 95\% CI 2.21-32.31) was favorable prognostic factor.

In 22 patients re-operation was performed due to local relapse or lymphadenopathy. Another 7 patients died due to the local relapse of the tumor, but since the disease was already in the advanced stage, those patients were not operated. The overall relapse rate was $12.1 \%$. The average time to the relapse was $90.74 \pm 85.4$ months (range, 1-288 months). The average time without any signs of the disease was 222.4 months (95\% CI: $197.8-$ 246.9). One-year disease free interval was $96.1 \%$, fiveyear was $91.1 \%$, ten-year was $86.2 \%$ and twenty-year disease free interval was $68.5 \%$ (Fig. 4).
According to the univariate analysis for disease free interval, age, capsular invasion, vascular invasion, surgeon's experience, ablative radioiodine treatment, hypertension and the presence of other malignancies were associated with shorter survival. Independent predictors for disease free interval were age at diagnosis (OR 1.4, 95\% CI 1.01-1.93), capsular invasion (OR 1.59, 95\% CI 1.13-2.22), as unfavorable prognostic factors, and surgeon experience (OR 0.62, 95\% CI 0.44-0.85) and presence of other malignancies (OR 0.58, 95\% CI 0.35-0.96) (Table 5), as favorable prognostic factors.

\section{Discussion}

Since Hurthle cell carcinoma is rare tumor, there is relatively small number of publications regarding this topic; furthermore, these publications are mostly based on the experiences of the individual institutions with a relatively small number of patients during various time intervals $[1,6-8]$. Even rarer are the papers that deal with population registers. The three largest series are studies of Nagar et al., Bhattacharyya et al. and Goffredo et al. who processed the registers from the United States [1, 2, 4]. To the best of our knowledge, this is the largest series of Hurthle cell carcinoma patients analyzed and operated at a single center.

The average age of our patients was 54; this is in concordance with other large Hurthle cell carcinoma studies: Petric et al. and Chindris et al. found that an average age at the time of surgery was 62 , Sugino et al. 58, Kushchayeva et al. 55.2 and Goffredo et al. 57.6. [2, 6, 9-11] According to the available literature, patients with Hurthle cell carcinoma are older when compared whit patients with other types of thyroid cancers. In a large population study, Goffredo et al. found that Hurthle cell carcinoma occurs almost ten years later than other well-

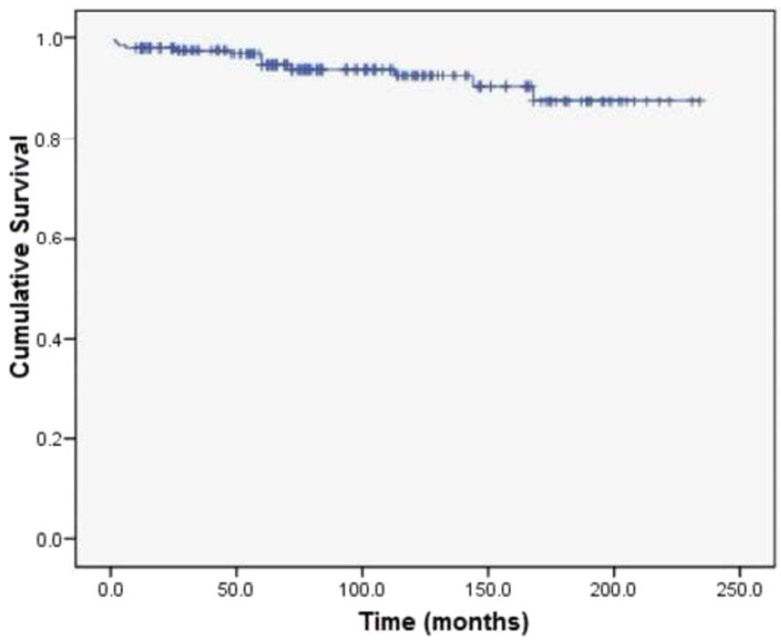

$\neg$ Survival Function

+ Censored 
Table 4 Univariate and multivariate statistical analysis of cancer specific survival

\begin{tabular}{|c|c|c|c|c|c|c|}
\hline \multirow[b]{2}{*}{ Factor } & \multicolumn{3}{|c|}{ Univariate } & \multicolumn{3}{|c|}{ Multivariate } \\
\hline & $p$ & OR & $95 \% \mathrm{Cl}$ & p & OR & $95 \% \mathrm{Cl}$ \\
\hline Gender (male vs. female) & 0,126 & 0,42 & $0,13-1,28$ & & & \\
\hline Age (years) (<54 vs. $\geq 55$ ) & 0,056 & 3,3 & $0,97-11,26$ & & & \\
\hline Disease duration (years) (<5 vs. $\geq 5$ ) & 0,941 & 1,04 & $0,34-3,19$ & & & \\
\hline T stadium ( $T 1$ and $T 2$ vs. $T 3$ and T4) & 0,03 & 4,18 & $1,14-15,19$ & & & \\
\hline $\mathrm{N}$ stadium (NO and Nx vs. N1a and N1b) & 0,451 & 2,19 & $0,28-16,98$ & & & \\
\hline Tumor type (minimally vs. widely invasive) & 0,684 & 0,78 & $0,24-2,54$ & & & \\
\hline Tumor size $(\mathrm{mm})(\leq 39$ vs. $>40)$ & 0,328 & 1,99 & $0,49-7,99$ & & & \\
\hline Capsular invasion (positive vs. no or minimal) & 0,903 & 1,09 & $0,29-4,07$ & & & \\
\hline Vascular invasion (positive vs. no or minimal) & 0,149 & 0,22 & $0,03-1,71$ & & & \\
\hline Number of tumor focuses (one vs. multicentric) & 0,374 & 1,72 & $0,52-5,73$ & & & \\
\hline Affection of both lobes (yes vs. no) & 0,05 & 3,09 & $0,97-9,85$ & 0,002 & 8,09 & $2,12-30,79$ \\
\hline Regional tumor infiltration (yes vs. no) & 0,027 & 0,28 & $0,92-0,86$ & & & \\
\hline Primary procedure (total thyroidectomy vs. less than total) & 0,049 & 3,24 & $0,99-10,64$ & 0,002 & 8,46 & $2,21-32,31$ \\
\hline Total thyroidectomy after lobectomy (yes vs. no) & 0,118 & 0,3 & $0,68-1,35$ & & & \\
\hline Type of procedure overall (total thyroidectomy vs. less than total) & 0,817 & 1,17 & $0,31-4,31$ & & & \\
\hline Reoperation due to relapse (yes vs. no) & 0,001 & 0,117 & $0,04-0,35$ & 0,001 & 0,10 & $0,03-0,39$ \\
\hline Surgeon's experience (years) (<10 vs. 10+) & 0,421 & 0,63 & $0,2-1,95$ & & & \\
\hline Radioiodine ablation (yes vs. no) & 0,921 & 1,12 & $0,1-12,45$ & & & \\
\hline Diabetes mellitus (yes vs. no) & 0,603 & 21,78 & $0,001-2,393,431$ & & & \\
\hline Hypertension (yes vs. no) & 0,292 & 0,53 & $0,16-1,71$ & & & \\
\hline Other malignancies (yes vs. no) & 0,519 & 23,03 & $0,002-315,487$ & & & \\
\hline Thyroglobulin (ng/mL) (<300 vs. >300) & 0,695 & 1,62 & $0,14-18,38$ & & & \\
\hline
\end{tabular}

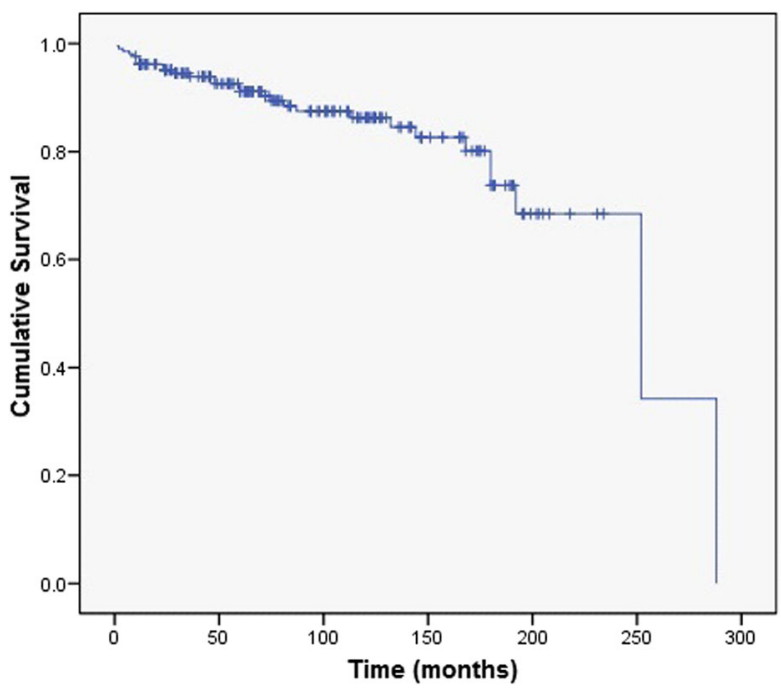

$-\neg$ Survival Function

+ Censored

Fig. 4 Kaplan-Meier disease free interval curve 
Table 5 Univariate and multivariate statistical analysis of disease free interval

\begin{tabular}{|c|c|c|c|c|c|c|}
\hline \multirow[b]{2}{*}{ Factor } & \multicolumn{3}{|c|}{ Univariate } & \multicolumn{3}{|c|}{ Multivariate } \\
\hline & $p$ & OR & $95 \% \mathrm{Cl}$ & $p$ & $\mathrm{OR}$ & $95 \% \mathrm{Cl}$ \\
\hline Gender (male vs. female) & 0,188 & 0,79 & $0,55-1,12$ & & & \\
\hline Age (years) (<54 vs. $\geq 55)$ & 0,001 & 1,65 & $1,22-2,22$ & 0,043 & 1,4 & $1,01-1,93$ \\
\hline Disease duration (years) ( $<5$ vs. $\geq 5$ ) & 0,073 & 0,75 & $0,55-1,02$ & & & \\
\hline T stadium ( $T 1$ and $T 2$ vs. $T 3$ and $T 4$ ) & 0,337 & 0,86 & $0,64-1,16$ & & & \\
\hline $\mathrm{N}$ stadium (NO and Nx vs. N1a and N1b) & 0,438 & 0,70 & $0,29-1,71$ & & & \\
\hline Tumor type (minimally vs. widely invasive) & 0,485 & 0,89 & $0,65-1,22$ & & & \\
\hline Tumor size $(\mathrm{mm})(\leq 39$ vs. $>40)$ & 0,723 & 1,06 & $0,77-1,44$ & & & \\
\hline Capsular invasion (positive vs. no or minimal) & 0,001 & 1,71 & $1,23-2,37$ & 0,007 & 1,59 & $1,13-2,22$ \\
\hline Vascular invasion (positive vs. no or minimal) & 0,002 & 1,64 & $1,19-2,23$ & & & \\
\hline Number of tumor focuses (one vs. multicentric) & 0,364 & 0,84 & $0,58-1,22$ & & & \\
\hline Affection of both lobes (yes vs. no) & 0,123 & 1,33 & $0,92-1,9$ & & & \\
\hline Regional tumor infiltration (yes vs. no) & 0,19 & 1,37 & $0,86-2,18$ & & & \\
\hline Primary procedure (total thyroidectomy vs. less than total) & 0,335 & 1,18 & $0,84-1,63$ & & & \\
\hline Type of procedure overall (total thyroidectomy vs. less than total) & 0,254 & 1,22 & $0,86-1,71$ & & & \\
\hline Surgeon's experience (years) (<10 vs. $10+)$ & 0,001 & 0,58 & $0,42-0,79$ & 0,003 & 0,62 & $0,44-0,85$ \\
\hline Radioiodine ablation (yes vs. no) & 0,026 & 0,69 & $0,49-0,95$ & & & \\
\hline Diabetes mellitus (yes vs. no) & 0,097 & 0,59 & $0,32-1,09$ & & & \\
\hline Hypertension (yes vs. no) & 0,009 & 0,67 & $0,5-0,9$ & & & \\
\hline Other malignancies (yes vs. no) & 0,001 & 0,45 & $0,27-0,73$ & 0,034 & 0,58 & $0,35-0,96$ \\
\hline Thyroglobulin (ng/mL) (<300 vs. $>300)$ & 0,976 & 1,01 & $0,55-1,83$ & & & \\
\hline
\end{tabular}

differentiated cancers: 57.6 vs. 48.9 years, respectively [2]. Also, Sugino et al. have found that Hurthle cell carcinoma develops ten years later even if compared to the follicular carcinomas: 58 vs. 48 years, respectively [10]. On the other hand, there are disagreements regarding the age difference between the Hurthle cell adenoma and Hurthle cell carcinoma. Study of Barnabei et al. and one study from our center showed that there was no difference regarding age (49 years), while study of LopezPenabad et al. showed that patients with Hurthle cell carcinoma are older at the time of surgery than patients with Hurthle cell adenomas, 51.8 years vs. 43.1 years [12-14].

The average age at the moment of death of the patients with Hurthle cell carcinoma in our series was 64.7 years, and this was more than 10 years less than the average life expectancy in Serbia (74.9 Eurostat Life expectancy at birth) [15]. On the contrary, patients who were operated for Hurthle cell carcinoma and died due to other reasons experienced the average life expectancy. So, based on these results, beside the fact that Hurthle cell carcinoma has low mortality rate, it can also be concluded that patients with aggressive disease and/or inadequately treated patients have shorter life expectancy.
Most of contemporary literature data agrees that the average tumor size at the time of surgery ranges from 25 to $48 \mathrm{~mm}[2,4,6,13]$. In our study, the average tumor size was $41 \mathrm{~mm}$. As the vast majority of endocrine system tumors, Hurthle cell carcinoma also occurs more frequently in females. In our study the female-to-male ratio was 3.6:1, while Mills et al. showed ratio of $1.6: 1$, Kushchayeva et al. 2.3:1, Nagar et al. 2:1 and Petric et al. $3.2: 1[1,6,8,11]$.

The surgical procedure of choice in the treatment of Hurthle cell carcinoma should be total thyroidectomy, so that adequate suppressive levothyroxine therapy and ablative radioiodine therapy for stages over T2 could be applied. Still, when procedure less than total thyroidectomy is performed, completion of total thyroidectomy is not always indicated. In our series, in $68.6 \%$ of patients a total thyroidectomy was conducted. In other series the percentage of total thyroidectomy ranges from $27.4 \%$ to $80 \%[2,8,10,11,16]$. At our Institution, the completion of thyroidectomy is performed in cases of suspected changes in the contralateral lobe, which tends to increase in spite of suppressive therapy with levothyroxine, or if lesions of the thyroid capsule were present, so ablative radioiodine therapy is indicated. Out of 66 patients who have initially undergone lobectomy, completion of 
thyroidectomy was performed in 21 . Out of those patients, Hurthle cell carcinoma focus was found on the contralateral side in 12 patients (57.1\%). In a large series of Sugino et al. among patients who have undergone completion of total thyroidectomy, in $12.8 \%$ focus of Hurthle cell carcinoma was found at the contralateral side [10].

In our study locoregional metastases were present in $7.7 \%$ of those patients in whom lymph nodes were extirpated during the primary surgery. This percentage is similar in comparison to the one found in a large population study, conducted by Goffredo et al. (5.3\%). [2] On the contrary, Sugino et al. found positive lymph nodes in $21.9 \%$ of patients, in a large series [10].

The percentage of patients who had a relapse in our study was $12.1 \%$. This percentage is among the lowest, when compared to the other studies that have researched Hurthle cell carcinoma, in which relapse was found in $10.5 \%$ to $43 \%$ of patients $[2,6,8]$. This can be explained by the good selection of patients, multimodal treatment approach along with an adequate use of radioiodine after total thyroidectomy, and by the fact that total thyroidectomy was performed in a relatively high percentage of patients in our study.

In our study, overall ten-year survival was $77.2 \%$, while cancer-specific survival was $92.5 \%$. Our results and the results from other similar studies regarding the overall survival and cancer-specific survival are shown in Table 6 $[1,2,4,6-8,10,11,14,16,17]$. A ten-year cancer-specific survival in other studies ranges from $49 \%$ to $93.1 \%$. There is a great number of factors that affect the disease specific survival, for example: in studies that were conducted in tertiary institutions patients are more likely to be in the advanced stages, so disease specific survival is shortened. Similarly, studies that include earlier periods, from earlier years, have lower percentages of survival. Thus, studies of Mills et al., Stojadinovic et al. and Lopez-Penabad et al., which include periods from '40-ies report disease-specific survival rates in a range of $64 \%$ to $73 \%$, while studies involving patients from the '70s and '80-ies report a significantly higher percentages, up to $90 \%$. The reason for better disease-specific survival rates in later years most likely lies in the fact that nowadays, tumors are revealed at an earlier stage, that less radical surgical procedures, such as bilateral subtotal lobectomy and Dunhill's procedure, were applied more at that time and that radioiodine was less frequently used. Besides, disease-specific survival rate is improved for other types of well-differentiated thyroid cancers: the study of Chow et al. showed improvement in survival rate in years between 1960 and 2000, in 1.348 patients with differentiated thyroid cancer [18]. However, the study of Goffredo et al. showed that the trend has stabilized in the last two decades, so Hurthle cell carcinoma's survival does not change, unlike other differentiated thyroid cancers [2]. Similar findings were presented by Roman et al. in a study that examined the survival of patients with medullary carcinoma: survival rates did not show significant changes during the period from 1973 to 2002 [19].

In present study, independent predictive factors for shorter overall survival were age over $55, \mathrm{~T} 3$ and T4 stadium, alterations in both thyroid lobes and the need for re-operation due to local relapse. When cancer specific survival was observed, multivariate regression analysis showed that affection of both thyroid lobes and need for reoperation due to local relapse were unfavorable prognostic factors and that total thyroidectomy as primary procedure was independent favorable predictor. Recent study conducted by Petric et al. showed that independent prognostic factors for cancer specific survival were

Table 6 Ten years survival in patients with Hurthle cell carcinoma

\begin{tabular}{|c|c|c|c|c|c|}
\hline & $\begin{array}{l}\text { Period of } \\
\text { study }\end{array}$ & $\begin{array}{l}\text { Number of } \\
\text { patients }\end{array}$ & $\begin{array}{l}\text { Overall survival } \\
(\%)\end{array}$ & $\begin{array}{l}\text { Cancer specific } \\
\text { survival (\%) }\end{array}$ & $\begin{array}{l}\text { Disease free } \\
\text { interval (\%) }\end{array}$ \\
\hline Haigh et al. (SEER) [16] & 1988-1993 & 172 & 73 & & \\
\hline Lopez-Penabad et al. [14] & 1944-1995 & 89 & 55 & 64 & \\
\hline Bhattacharyya et al. (SEER) [4] & 1973-1998 & 555 & 71.1 & & \\
\hline Stojadinovic et al. [7] & 1940-2000 & 56 & & 73 & 61 \\
\hline Kushchayeva et al. [11] & 1976-2002 & 33 & & 49 & 40.5 \\
\hline Mills et al. [8] & $1946-2003$ & 62 & & 64 & 43 \\
\hline Jillard et al. (National Cancer Database) [17] & 1998-2006 & 1909 & 70.7 & & \\
\hline Nagar et al. (SEER-9) [1] & 1975-2009 & 1416 & 77.1 & & \\
\hline Goffredo et al. (SEER) [2] & 1988-2009 & 3311 & & 91 & \\
\hline Sugino et al. [10] & 1989-2010 & 73 & & 93.1 & \\
\hline Petric et al. [6] & $1972-2011$ & 108 & & 88 & 68 \\
\hline Our study & 1995-2014 & 239 & 77.2 & 92.5 & 86.2 \\
\hline
\end{tabular}

SEER surveillance, epidemiology, and end results 
age, distant metastases and residual tumor after surgery [6]. Bhattacharyya et al. found that age at the time of diagnosis, male gender and increasing tumor size were statistically significantly associated with shorter cancer specific survival in multivariate analysis [4]. Results of a large, population-based study that included 3311 patients found that age at diagnosis over 45 , marital status, tumor size $\geq 4 \mathrm{~cm}$ and extrathyroidal invasion were independently associated with lower cancer specific survival. Also, those authors showed that patients who were not surgically treated had worse prognosis [2]. Based on the results of other studies, independent negative predictors for cancer specific survival are older age, tumor size $>4 \mathrm{~cm}$, positive extrathyroid invasion, higher $\mathrm{T}$ stadium, capsular invasion, less extensive surgery and the presence of more than one focuses, residual tumor tissue following surgery and regional and/or distant metastases $[7,8,14]$.

In our study, a ten-year disease free interval was $86.2 \%$. In the available literature there are insufficient data, so a ten-year disease free interval varies in a range from 40.5 to $68 \%$ (Table 6) $[6-8,11]$. Likewise, only few studies investigated prognostic factors for disease free interval, particularly - independent predictors. Petric et al. found that male gender, age over 45 , regional metastasis at the moment of primary surgery and residual tumor after surgery were associated with unfavorable prognosis [6]. Stajadinovic et al., analyzed 60 years of experience in the treatment of patients with Hurthle cell carcinoma and found that extrathyroidal invasion and lymphonodal metastases were associated with shorter disease free interval [20]. Results from our study showed that age over 55 , positive capsular invasion, surgeon's experience and the presence of nonthyroid malignancies were predictors of shorter disease free interval.

The fact that the study was conducted in a single center, that the data are uniform and that all patients were operated with the same doctrine, should be considered as advantages of the current study.

Our study has several limitations. The main limitation certainly represents retrospective design; also, this study is observational and not randomized. Furthermore, there is a relatively small number of subjects. We believe that it would be useful to perform multicentric study with a higher number of patients.

\section{Conclusions}

Hurthle cell carcinoma is rare tumor with an encouraging prognosis. After adequate surgical treatment, relapses are rare. A ten-year cancer specific survival is $92 \%$ and even $86 \%$ of patients have no signs of relapse ten years after surgery.

\begin{abstract}
Abbreviations
Cl: Confidence interval; OR: Odds ratio; SD: Standard deviation; TNM: Tumor Nodes Metastasis
\end{abstract}

\section{Acknowledgements}

Not applicable.

Funding

None.

\section{Availability of data and materials}

Data underlying the conclusions made in this paper can be obtained upon request to the corresponding author.

\section{Authors' contributions}

$\mathrm{BO}, \mathrm{VZ}$ and $\mathrm{MJ}$ designed and performed the research. ZL, VD, DM, NS, AF, ZG and $B R$ were responsible for data acquisition. $M J, A D, V D, I P$, and $V Z$ analyzed and interpreted data. BO, MJ, VZ and ZG wrote the paper. ZL, AD, VD, IP, BR, $\mathrm{DM}, \mathrm{NS}$ and AF reviewed the manuscript and revised it critically. BO integrated the entire study. All authors read and approved the final manuscript.

Competing interests

The authors declare that they have no competing interests.

Consent for publication

Not applicable.

\section{Ethics approval and consent to participate}

The study was approved by the ethical commission board from the Faculty of Medicine, Belgrade. Due to the retrospective design of the study the local ethic committee confirmed, that informed consent was not necessary from participants.

\section{Publisher's Note}

Springer Nature remains neutral with regard to jurisdictional claims in published maps and institutional affiliations.

\section{Author details}

${ }^{1}$ Emergency Center, Clinical Center of Serbia, Pasterova 2, Belgrade 11000, Serbia. ${ }^{2}$ Center for Endocrine Surgery, Clinical Center of Serbia, Pasterova 2, Belgrade 11000, Serbia. ${ }^{3}$ Faculty of Medicine, University of Belgrade, Dr Subotica 8, Belgrade 11000, Serbia. ${ }^{4}$ Clinic for Thoracic Surgery, Clinical Center of Serbia, Pasterova 2, Belgrade 11000, Serbia. ${ }^{5}$ Clinical Center of Montenegro, Department of Endocrine Surgery, University of Montenegro, Podgorica, Montenegro.

Received: 2 August 2016 Accepted: 17 May 2017

Published online: 25 May 2017

\section{References}

1. Nagar S, Aschebrook-Kilfoy B, Kaplan EL, Angelos P, Grogan RH. Hurthle cell carcinoma: an update on survival over the last 35 years. Surgery. 2013; 154(6):1263-71.

2. Goffredo P, Roman SA, Sosa JA. Hurthle cell carcinoma: a population-level analysis of 3311 patients. Cancer. 2013; 1;119(3):504-11.

3. Ganly I, Ricarte Filho J, Eng S, Ghossein R, Morris LG, Liang Y, et al. Genomic dissection of Hurthle cell carcinoma reveals a unique class of thyroid malignancy. J Clin Endocrinol Metab. 2013:98(5):E962-72.

4. Bhattacharyya N. Survival and prognosis in Hürthle cell carcinoma of the thyroid gland. Arch Otolaryngol Head Neck Surg. 2003;129(2):207-10.

5. Shaha AR. TNM classification of thyroid carcinoma. World J Surg. 2007;31(5): 879-87.

6. Petric R, Gazic B, Besic N. Prognostic factors for disease-specific survival in 108 patients with Hürthle cell thyroid carcinoma: a single-institution experience. BMC Cancer. 2014;14:777.

7. Stojadinovic A, Hoos A, Ghossein RA, Urist MJ, Leung DH, Spiro RH, et al. Hürthle cell carcinoma: a 60-year experience. Ann Surg Oncol. 2002;9:197-203.

8. Mills SC, Haq M, Smellie WJ, Harmer C. Hürthle cell carcinoma of the thyroid: retrospective review of 62 patients treated at the Royal Marsden Hospital between 1946 and 2003. Eur J Surg Oncol. 2009;35:230-4. 
9. Chindris AM, Casler JD, Bernet VJ, Rivera M, Thomas C, Kachergus JM, et al. Clinical and molecular features of Hürthle cell carcinoma of the thyroid. J Clin Endocrinol Metab. 2015;100(1):55-62.

10. Sugino K, Kameyama K, Ito K, Nagahama M, Kitagawa W, Shibuya H, et al. Does Hürthle cell carcinoma of the thyroid have a poorer prognosis than ordinary follicular thyroid carcinoma? Ann Surg Oncol. 2013;20(9):2944-50,

11. Kushchayeva Y, Duh Q-Y, Kebebew E, Clark OH. Prognostic indications for Hürthle cell cancer. World J Surg. 2004;28:1266-70.

12. Paunovic I, Krgovic K, Tatic S, Diklic A, Zivaljevic V, Kalezic N, et al. Surgery for thyroid Hürthle cell tumours-a single institution experience. Eur J Surg Oncol. 2006;32(4):458-61.

13. Barnabei A, Ferretti E, Baldelli R, Procaccini A, Spriano G, Appetecchia M. Hurthle cell tumours of the thyroid. Personal experience and review of the literature. Acta Otorhinolaryngol Ital. 2009;29(6):305-11.

14. Lopez-Penabad L, Chiu AC, Hoff AO, Schultz P, Gaztambide S, Ordoñez NG, et al. Prognostic factors in patients with Hürthle cell neoplasms of the thyroid. Cancer. 2003;97(5):1186-94.

15. Jakovljevic MM, Arsenijevic J, Pavlova M, Verhaeghe N, Laaser U, Groot W. Within the triangle of healthcare legacyes: comparing the performance of south-eastern European health systems. J Med Econ. 2017;17:1-10.

16. Haigh $\mathrm{Pl}$, Urbach DR. The treatment and prognosis of Hürthle cell follicular thyroid carcinoma compared with its non-Hürthle cell counterpart. Surgery. 2005;138(6):1152-7.

17. Jillard CL, Youngwirth L, Scheri RP, Roman S, Sosa JA. Radioactive iodine treatment is associated with improved survival for patients with Hürthle cell carcinoma. Thyroid. 2016:26(7):959-64.

18. Chow SM, Law SC, Au SK, Mang O, Yau S, Yuen KT, et al. Changes in clinical presentation, management and outcome in 1348 patients with differentiated thyroid carcinoma: experience in a single institute in Hong Kong, 1960-2000. Clin Oncol (R Coll Radiol). 2003;15(6):329-36.

19. Roman S, Lin R, Sosa JA. Prognosis of medullary thyroid carcinoma: demographic, clinical, and pathologic predictors of survival in 1252 cases. Cancer. 2006;107(9):2134-42.

20. Stojadinovic A, Ghossein RA, Hoos A, Urist MJ, Spiro RH, Shah JP, et al. Hürthle cell carcinoma: a critical histopathological appraisal. J Clin Oncol. 2001;19:2616-25.

\section{Submit your next manuscript to BioMed Central and we will help you at every step:}

- We accept pre-submission inquiries

- Our selector tool helps you to find the most relevant journal

- We provide round the clock customer support

- Convenient online submission

- Thorough peer review

- Inclusion in PubMed and all major indexing services

- Maximum visibility for your research

Submit your manuscript at www.biomedcentral.com/submit

) Biomed Central 